\title{
Study on the Time-lag Failure of Sandstone With Different Degrees of Unloading Damage
}

\author{
Qiao Jiang ${ }^{1,2}$, Jianlin $\mathrm{Li}^{1,2}$, Zuosen Luo ${ }^{2}$, Xiaoliang Xu², Eleyas Assefa ${ }^{3}$, Huafeng Deng 2,* \\ ${ }^{1}$ College of Hydraulic\& Environmental Engineering, \\ China Three Gorges University, \\ Yichang City, Hubei Province, 443002, China \\ 2 Key Laboratory of Geological Hazards on Three Gorges Reservoir Area of Ministry of Education, \\ China Three Gorges University, \\ Yichang City, Hubei Province, 443002, China \\ ${ }^{3}$ College of Architecture and Civil Engineering, \\ Addis Ababa Science and Technology University, Ethiopia \\ * Corresponding author, e-mail: dhf8010@ctgu.edu.cn
}

Received: 07 October 2018, Accepted: 12 December 2018, Published online: 16 January 2019

\begin{abstract}
The unloading effect of rock mass excavation is an inevitable practice, and it's often characterized by a relatively large-scale engineering hazard with a noticeable time lag.

A set of unloading triaxial tests were conducted on a sandstone rock to establish the deformation law and the threshold time. Based on the renormalization group theory, the unloading sandstone model was developed by considering the interaction between particles. Similarly, a logistic model was used to predict the unloading damage of sandstone. The unloading time lag damage of sandstone rock was predicted by using the damage threshold. The research shows that: (1) The higher the degree of unloading, the shorter the timelag failure. (2) The damage range of critical values was optimized. (3) The error between the predicted value and the experimental value of the time threshold was almost less than $5 \%$, the prediction result was found to be good, and the employed logistic evolution model was reasonable. The findings of this research provide a prediction method and precise information about the mechanism of unloading time lag deformation. Therefore, it can be used as a reference for excavation-support design of underground structures.
\end{abstract}

\section{Keywords}

unloading damage, time-lag, renormalization group theory, logistic model

\section{Introduction}

In many engineering problems, unloading of rock mass due to excavation is an inevitable practice. Ha, et al. [1] developed unloading rock mass mechanics theory. After the excavation of the rock mass, a significant amount of damage will develop. Some even evolved into engineering disasters, such as rock burst, and wall caving. The unloading deformation of rock mass will occur in modern hydraulic engineering, mining engineering, underground transportation engineering and deep military engineering construction, which will often result in significant casualties and economic loss. It is a difficult problem to be solved in the ongoing engineering projects. The deformation and failure of the rock mass don't take place immediately after the excavation. [2-3] As shown in Figure 1, the Lu Niba Mountain Tunnel was repaired after excavation from July
22 to 28, 2011, until a severe rock burst occurred in the exit section on August 7, 2011. According to Yang et al., the maximum rock burst occurred after $5 \sim 45 \mathrm{~h}$ of excavation, In Jinping II hydropower station. He holds that time delay is a universal law and intrinsic nature of rock burst [4].

At present, actual and experimental studies can be used to study the time lag phenomenon. Ömer Aydan [5] studied time-dependency in rock mechanics and rock engineering cover the spectrum including coupled processes of thermal, hydrological and diffusions in rocks. Raheb Bagherpour, et al. [6] hold that Squeezing and rock burst stands for large time dependent convergence during tunnel excavation. Zhang Lijie [7] studied the impact of time-lagged fracture on marble and limestone rocks under high-stress conditions through laboratory and numerical experiments. 

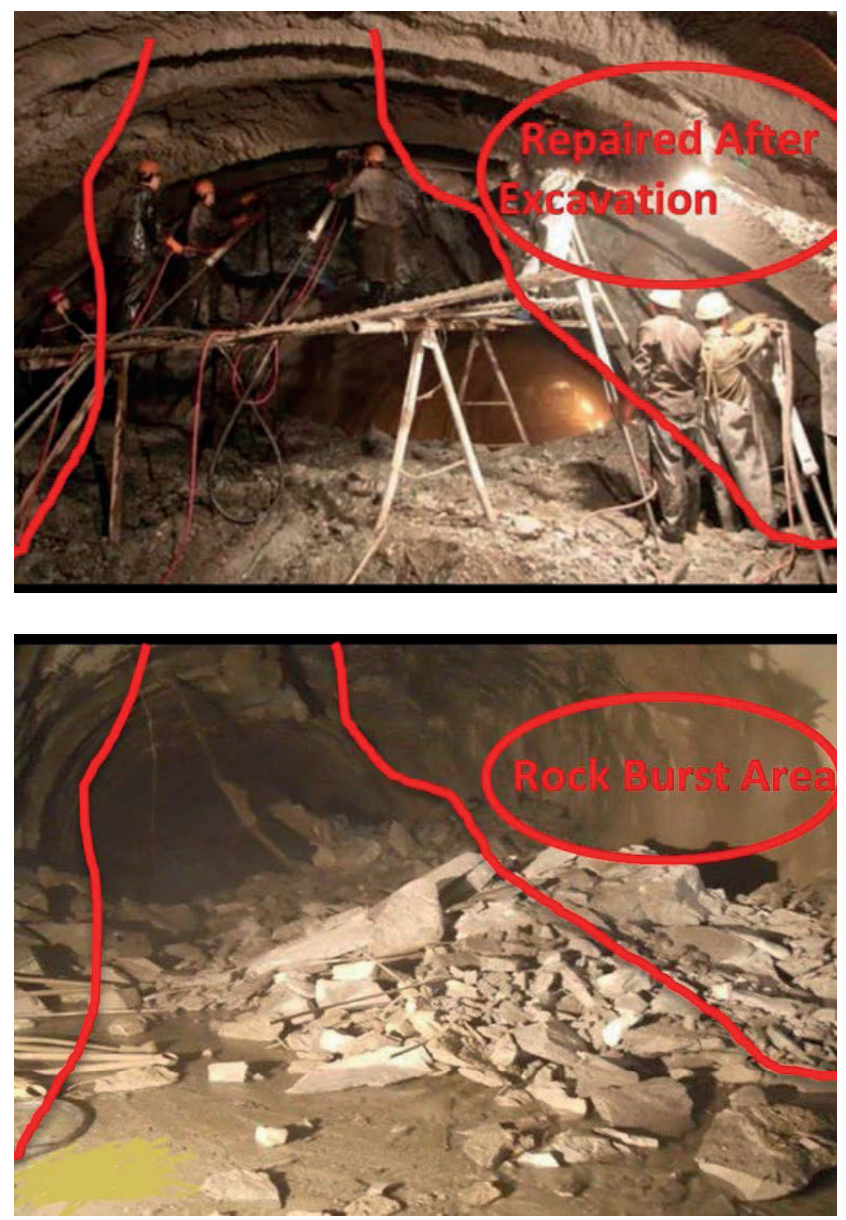

Fig. 1 Typical rock burst in Lu Niba Mountain Tunnel

The excavation and support systems of underground caverns were numerically simulated, considering the influence of high stress and duration of failure. During the excavation of underground powerhouse: the laws of deformation, different types of failure modes and key locations of the mechanical behavior of the surrounding rocks can be studied. The excavation-support design methods and monitoring arrangements of the underground powerhouse are improved. Su Chengdong et al. [8] conducted a comparative experiment on coal specimens by using uniaxial compression and grading loading tests to investigate the time-delay stress characteristics of coal wall slabs in mining face. Uniaxial compression test results provided higher values of mechanical parameters The mechanical parameters of coal specimens have a higher level ratio of the graded loading stress, shorter time delay damage, and obvious time lag. Fan Yong et al. [9] determined the energy dissipation law of tunnel surrounding rock under different excavation modes and evaluated the grade of rock burst based on the released elastic strain energy. The research shows that the transient unloading induced by the drilling and blasting method exacerbates the cracking effect of the surrounding rock compared with the quasi-static unloading caused by the excavation of the tunnel boring machine, which leads to the increase of the energy dissipation value during the cracking process. After excavation, the elastic strain energy of the surrounding rock and the likelihood of time-delay rock burst will decrease. However, due to the high energy aggregation characteristics of transient unloading process, the elastic strain energy, and the risk of immediate rock burst can be increased in the drilling and blasting technique. Ma Tianhui et al. [10] conducted an acoustic emission-assisted rock triaxial creep test and measured on-site micro-fractures around the tunnel surrounding rock to investigate the time-lagged rock burst. Micro-fracture precursors and its spatial-temporal evolution of tunnel surrounding rock during the creep process are studied. Hachimi Dahhaoui, et al. [11] studied creep behavior of argillaceous rock, and proposed time dependent modeling is based on a numerical homogenization method. The results show how numerical homogenization method is capable of effectively modelling macroscopic creep deformation.

The creep damage model of rock mass under high stress was constructed based on the evolution law of unloading creep deformation and the characteristics of the develop-mental stage of creep rate with time.

Many scholars studied the time lag of unloading deformation, failure of a rock mass, and rock burst and laid a foundation for this research. However, there are few reports on the time-delay damage of rock mass with different unloading degree of damage. The research on the time-delay failure mechanism of unloading damaged rock mass is still insufficient. Based on this, triaxial unloading tests were performed on sandstone rock to capture the effect of different degree of unloading damages on its time-delay damage characteristics.

\section{Experimental programs}

A typical sandstone rock from the Three Gorges reservoir area was used to meet the objectives of this paper. The cylindrical specimens were $50 \mathrm{~mm}$ in diameter by $100 \mathrm{~mm}$ in height. The specimens were screened based on their longitudinal wave velocities and rebound values [12].

The conventional triaxial compression and unloading tests were carried out on the natural state of rock samples. At $20 \mathrm{MPa}$ confining pressure, the triaxial compressive strength of the sandstone was $250 \mathrm{MPa}$, and the failure yielding unloading confining pressure was 12.5 $\mathrm{MPa}$. 
Table 1 Statisticaldata of time-lagged failure tests

\begin{tabular}{lcccc}
\hline $\begin{array}{l}\text { Unloading } \\
\text { values }\end{array}$ & $\begin{array}{c}\text { Loading } \\
\text { deviatoric } \\
\text { stresses } / \mathrm{MPa}\end{array}$ & $\begin{array}{c}\text { Cumulative } \\
\text { deformation } \\
\text { energy } / \mathrm{MJ} / \mathrm{m}^{3}\end{array}$ & $\begin{array}{c}\text { Elastic } \\
\text { energy / } \\
\mathrm{MJ} / \mathrm{m}^{3}\end{array}$ & $\begin{array}{c}\text { Duration of } \\
\text { failure/s }\end{array}$ \\
\hline $70 \%$ & 160.250 & 1.487 & 0.600 & 489.698 \\
$80 \%$ & 161.000 & 1.258 & 0.664 & 159.907 \\
$85 \%$ & 161.375 & 1.165 & 0.730 & 72.687 \\
$90 \%$ & 161.750 & 1.048 & 0.775 & 30.504 \\
$100 \%$ & 162.500 & 0.906 & 0.794 & 0.000 \\
\hline
\end{tabular}

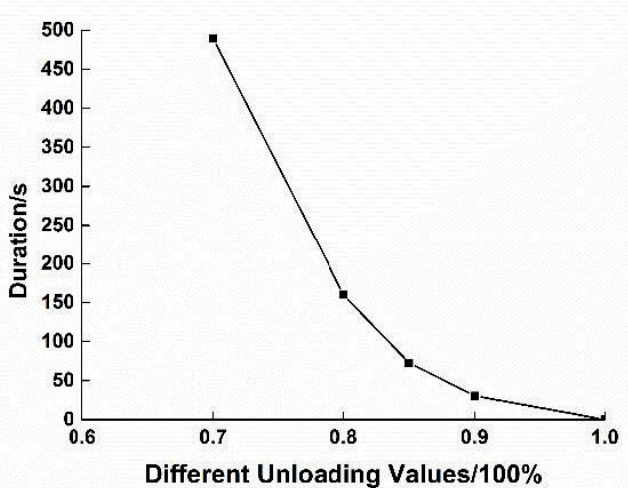

Fig. 2 Time-lagged failure duration curve of sandstone with different unloading values

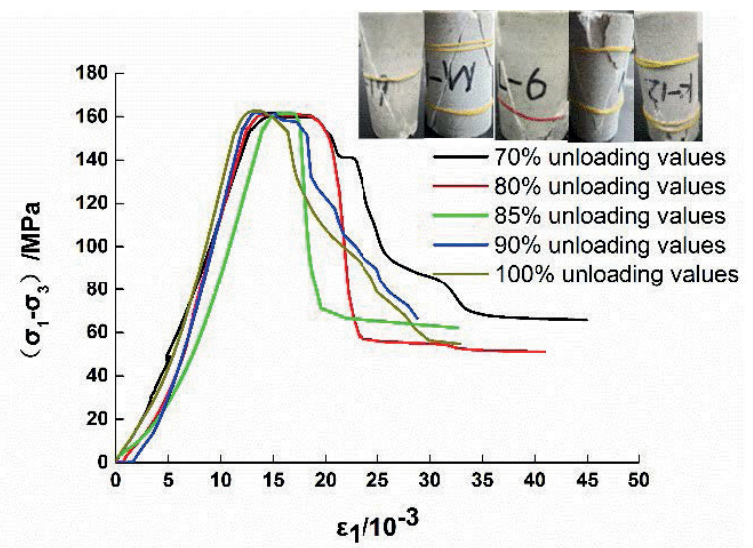

Fig. 3 Time-lagged stress-strain curves for different unloading values

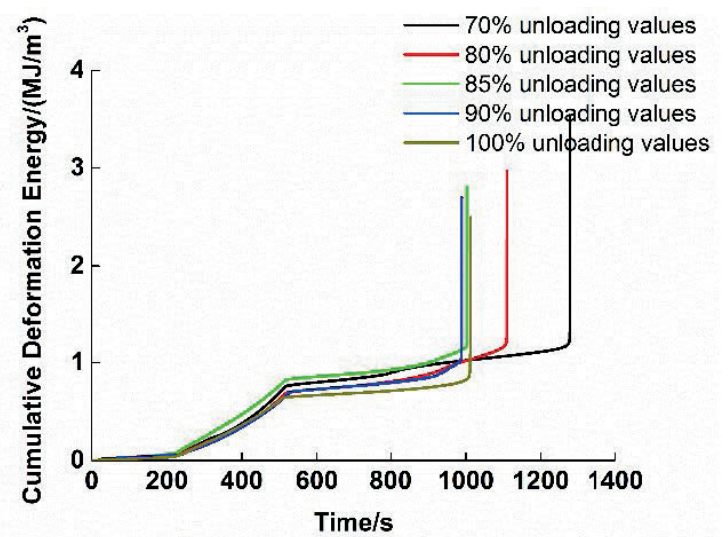

Fig. 4 Energy accumulation curve for different unloading values

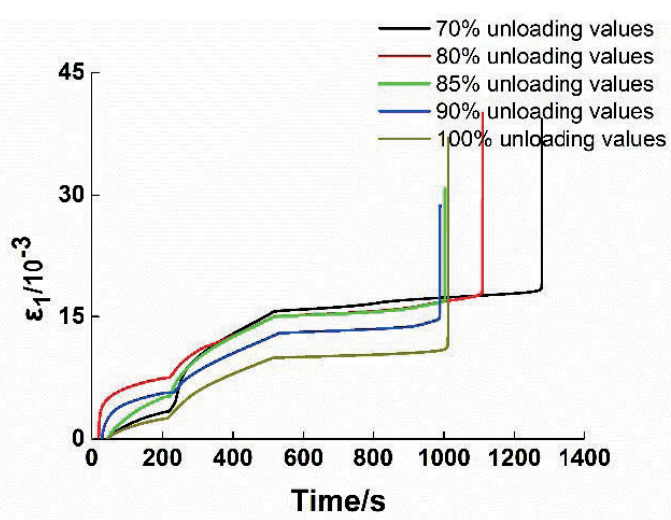

Fig. 5 Axial strain-time curve for different unloading values

On this basis, the time-delay damage of rock under different percentages of unloading $(70 \%, 80 \%, 85 \%, 90 \%$, and $100 \%$ ) was carried out. The testing procedures are described herein under:

The specimens were loaded at $70 \%$ of the triaxial compressive strength while the axial stress was constant. The unloading confining pressure was specified by using 4 different levels (14.75 MPa, $14 \mathrm{MPa}, 13.625 \mathrm{MPa}$, and 13.25 MPa). Different levels of unloading pressure $(70 \%, 80 \%$, $85 \%$, and $90 \%$ ) were applied until failure while the stress level was constant. The duration of time-lagged failure can be calculated at a particular confining pressure (at $100 \%$ of unloading the corresponding value is 0 ).

\section{Test results}

\subsection{Effect of time}

Figure 2-5 exhibits the duration curve, time-strain curve, cumulative deformation energy-time curve and axial strain-time curve of sandstone rock at different unloading values. Important test results are tabulated herein under (Table 1).

As is seen in above:

(1) Cracks are visible on the faces of rock specimens (Figure 2-3). The higher the unloading value, the shorter the time it takes to destroy, from $489.698 \mathrm{~s} \sim 30.504 \mathrm{~s}$, the higher the degree of rock fragmentation, and the failure surface evolves from a single shear fracture to a multi-fork shear fracture, accompanied by a large amount of white powder. In particular, a relatively complete sample (P19) with $70 \%$ unloading value has a failure time of 489.698 s. The time lag has a particular relationship with the integrity of the rock sample. Moreover, the time lag is also closely related to the initial unloading value. At different unloading values, the stress-strain curves are basically the same. There is no clear peak point. However, a complete failure occurred after the increase of stress-constant strain. 
(2) Compared with the compression test in the literature [4 7], the failure time of this test is obviously small, indicating that the unloading damage has a significant effect on the time-lag damage time. The reason is mainly due to the increase of the damage and the decrease of the strength after the excavation of the rock mass. The duration of the damage is obviously less than the intact rock sample.

(3) The cumulative deformation energy of the rock sample decreases with the increase of the unloading value, from $1.487 \mathrm{MJ} / \mathrm{m}^{3}$ to $0.906 \mathrm{MJ} / \mathrm{m}^{3}$ and the axial strain gradually decreases (Fig. 4-5). At failure, The cumulative energy and deformation are relatively small. The elastic energy gradually increases from $0.600 \mathrm{MJ} / \mathrm{m}^{3}$ to $0.794 \mathrm{MJ} / \mathrm{m}^{3}$. In fact, at a higher unloading value, internal cracks and failure of specimens cannot be fully developed. Besides, the accumulated elastic energy inside the rock specimen is increasing.

\subsection{Effect of time}

Similar to creep curves, the deformation-time curves showed three different stages [4, 8]: the initial deformation stage, constant velocity deformation stage, and accelerated deformation stage. An enlarged view of the deformation-time curve is shown in Figure 6-9. Typical results are herein under.

As is seen in Figure 6-9:

(1) With the increase of the unloading value, the ratio of the initial deformation stage to the duration of failure is reduced from $14.9 \%$ to $0 \%$, and the accelerated deformation stage is increased from $7.5 \%$ to $14.1 \%$. After the unloading value reaches $85 \%$, there is only constant velocity deformation stage and accelerated deformation stage. As the value of unloading increases, the internal damage of the rock becomes significant, and the deformation resistance of the rock reduced. As a result, the initial deformation stage reduced and the accelerated deformation stage increased.

(2) Similar to the creep curves, the time-lag curves have three stages. However, there are obvious differences between them. The stress value of the time-delay curve is generally very close to the peak value, and the stress value in the accelerated creep phase is smaller than the peak stress value. Crystal dislocation slip results creep, and accumulation of internal cracks yields time-lag damage. In the accelerated deformation stage, the time-delay curve is steeper than the creep curve.

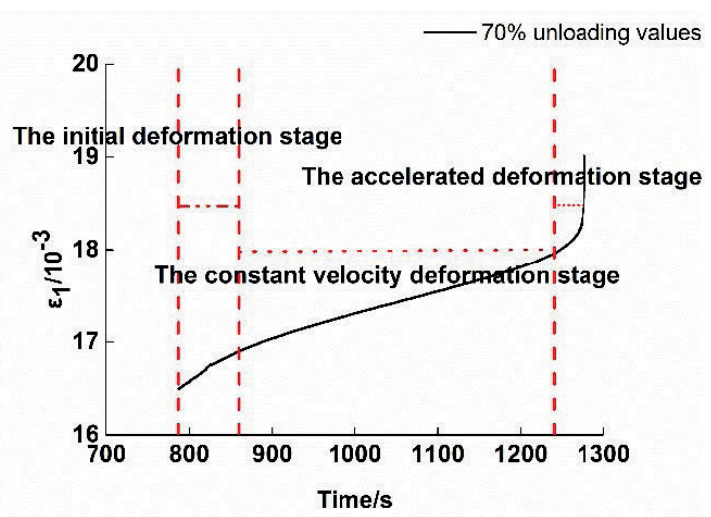

Fig. 6 Partial enlarged view of time-delayed failure at 70\% unloading value

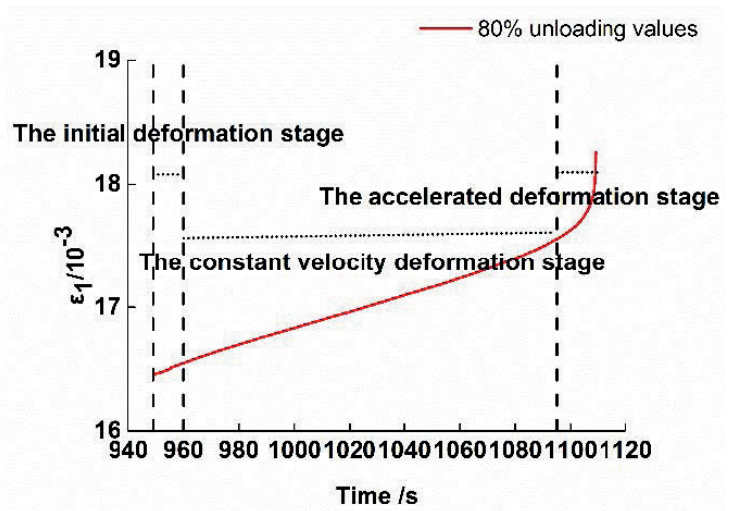

Fig. 7 Partial enlarged view of time-delayed failure at $80 \%$ unloading value

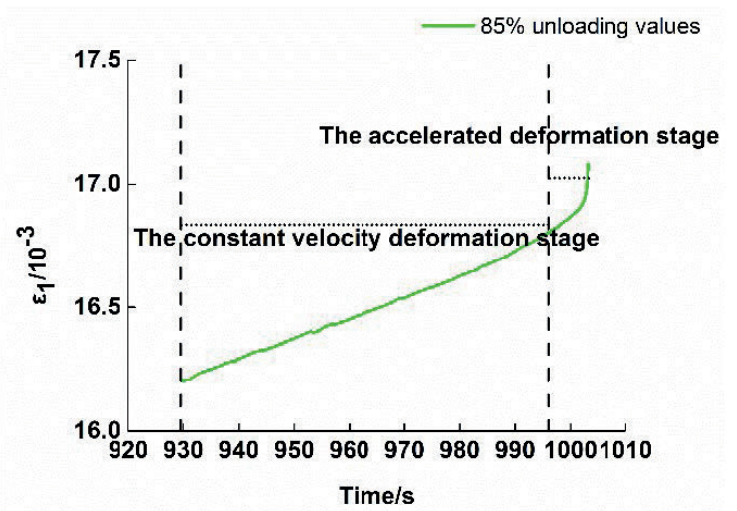

Fig. 8 Partial enlarged view of time-delayed failure at $85 \%$ unloading value

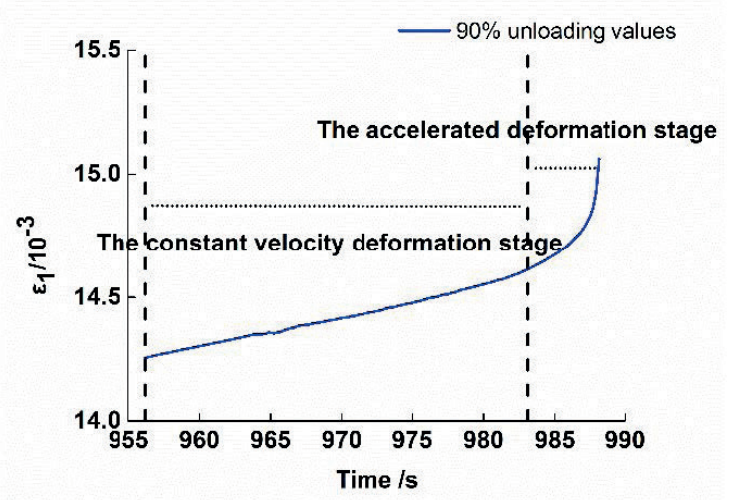

Fig. 9 Partial enlarged view of time-delayed failure at 90\% unloading value 

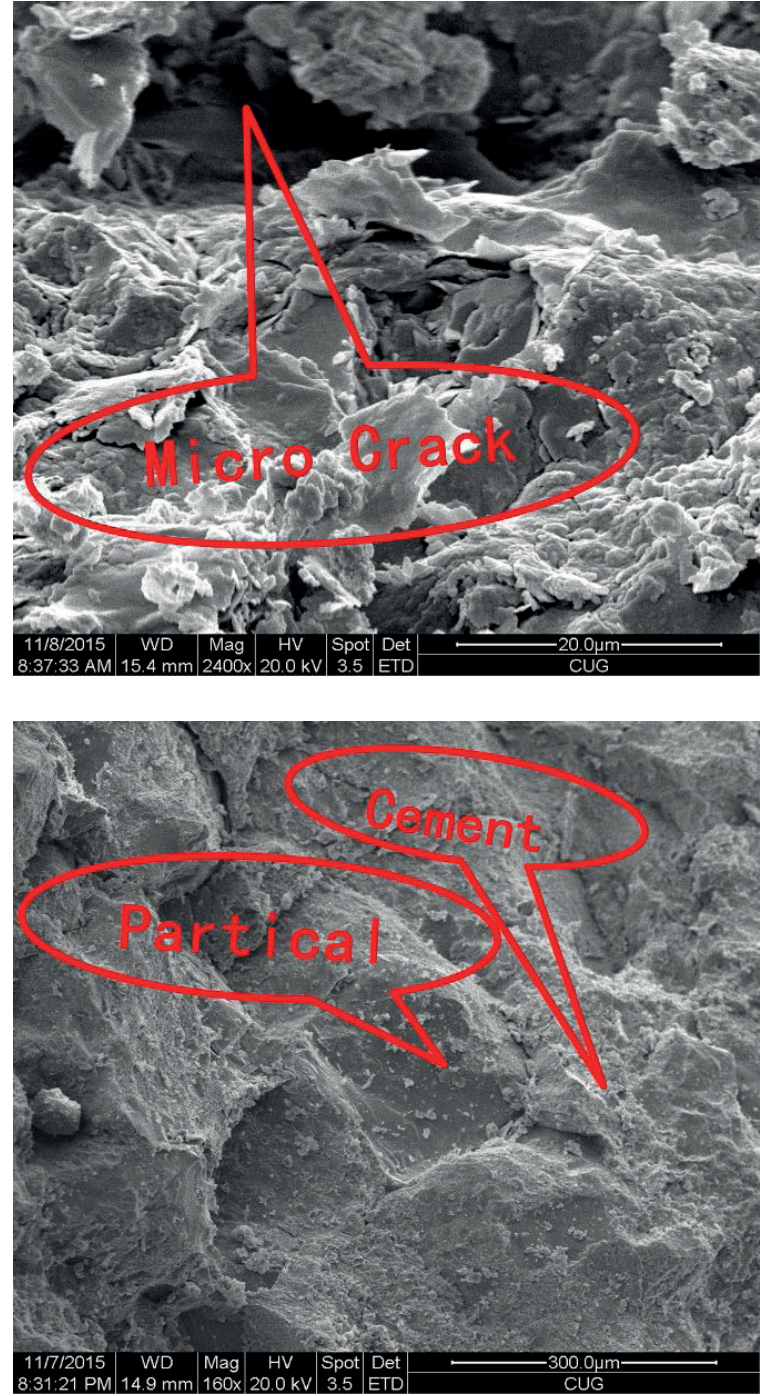

Fig. 10 Microscopic structure of unloading damaged sandstone

\section{Critical damage value of sandstone based on renormalization group method}

In order to predict the duration of the time-lagged failure, it is necessary to obtain the damage threshold of the prediction model. The critical value of the variable is called the percolation threshold. Percolation is a natural phenomenon. When the variable that plays a decisive role in the system reaches a threshold, the state of the system is abrupt. There exist percolation phenomenon and damage threshold in rock damage process under stress environment. The renormalization group method is an effective method to study the percolation threshold [13-15]. For rocks, it's a collection of granular skeleton and cementite. The strength of cemented rock is positively related to its cementite. For strong rocks cement is part of the skeleton [16]. As for the engineering rock, it will inevitably cause different degrees of unloading damage

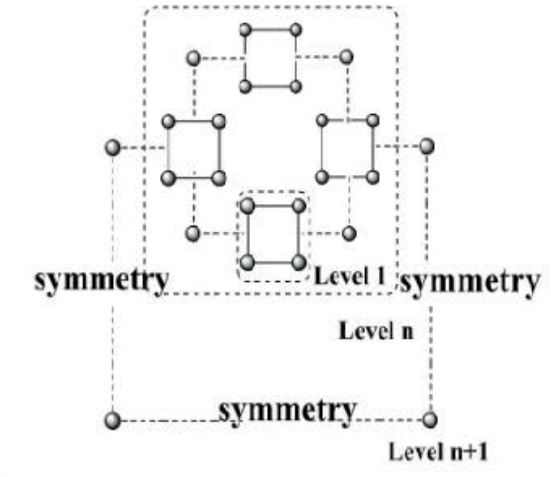

$Q \rightarrow$ Particle skeleton $>$ Cement component

Fig. 11 Renormalization model of unloading damaged sandstone

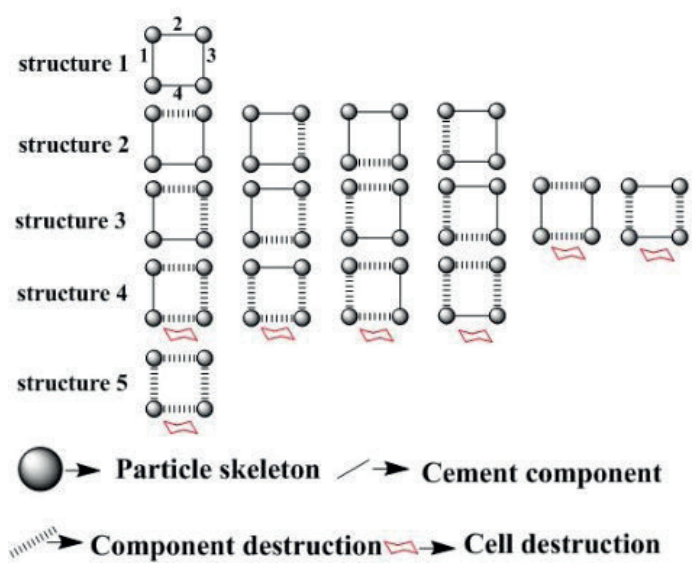

Fig. 12 Five configurations of unloading damaged sandstone for primary cells

and decrease in strength after excavation and unloading. At this time, the cementite is not part of the grain skeleton, and it has low strength. This paper employs the renormalization model of granular rock developed by Liu Zhen, et al. [17]. However, this study doesn't consider the interaction between the particles. There is a stress concentration at the nearby member due to particle damage, and the acting force assigned to the adjacent cementite member. OlamiZ [18] used a parameter in the OFC model of self-organized criticality to indicate the degree of interaction between units. Based on this, the author believes that an interaction coefficient $\mathrm{r} \in(0-1)$ can be used to characterize the influence degree of particle components. Fig. 10 shows the unloading microstructure damage of sandstone rock. Hence, the renormalization model of the unloading damage established in Fig. 11-12.

Due to the high degree of unloading of the rock, significant internal voids or damage resulted (with small $r$ value). Therefore, the $r$ value can be used to characterize the degree of interaction between different unloading degrees of cemented members. $P$ stands for the probability 
of damage of a cemented member 2, and $r P$ represents the probability of damage of 1or 3 . For the primary unit, the probability of damage can be expressed as follows:

For the first configuration, the probability of failure is: 0

For the second configuration, the probability of failure is: 0

For the third configuration, the probability of failure is: $2 p^{2} \times(1-p)^{2}+4 p^{2} \times(1-p)^{2} \times(r p) \times(1-r p)$.

For the fourth configuration, the probability of failure is: $4 p^{3} \times(1-p)$.

For the fifth configuration, the probability of failure is: $p^{4}$.

Therefore, the probability of damage for the primary cell is:

$$
\begin{aligned}
& p_{1}=2 p_{0}{ }^{2} \times\left(1-p_{0}\right)^{2}+4 p_{0}{ }^{2} \times\left(1-p_{0}\right)^{2} \times\left(r p_{0}\right) \times\left(1-r p_{0}\right)+ \\
& 4 p_{0}{ }^{3} \times\left(1-p_{0}\right)+p_{0}{ }^{4}
\end{aligned}
$$

During renormalization, the probability of cell damage at $(n+1)^{\text {th }}$ scale is $P_{n+1}$ :

$$
\begin{aligned}
& p_{n+1}=2 p_{n}{ }^{2} \times\left(1-p_{n}\right)^{2}+4 p_{n}{ }^{2} \times\left(1-p_{n}\right)^{2} \times\left(r p_{n}\right) \times\left(1-r p_{n}\right)+ \\
& 4 p_{n}{ }^{3} \times\left(1-p_{n}\right)+p_{n}{ }^{4}
\end{aligned}
$$

The damage $P n$ value of sandstone (Figure 13) for different degrees of damage is [0.500, 0.618]. After fitting, $p_{n}=0.141 \times e^{\left(\frac{-r}{0.505}\right)}+0.477$, and the correlation coefficient was 0.999 .

For verification purpose, the damage value is calculated based on the experimental data. Rock damage is a continuous process of strength weakening and plastic deformation. Therefore, in the residual damage value $D_{r}$, the deformation modulus was investigated, and only the initial damage existed. The authors consider the variation of deformation modulus in the full stress-strain curve of rock as the development of damage.

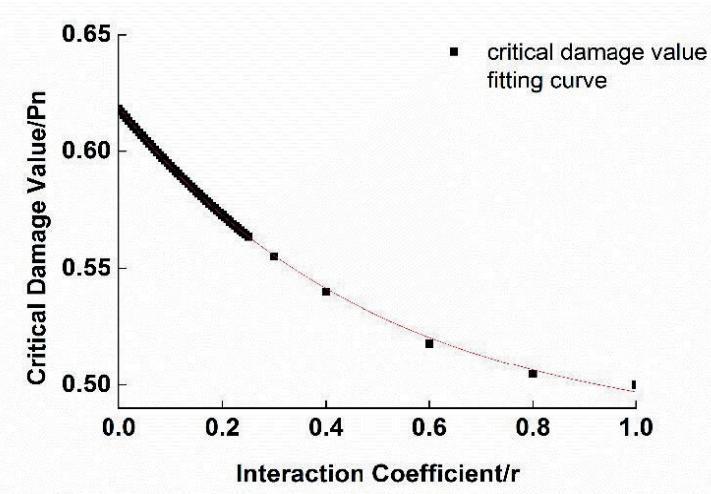

Fig. 13 Critical value curve for unloading damaged sandstone
The damage can be defined as:

$\mathrm{D}=1-\frac{E}{E_{m}}$

where, $E_{m}$ is the maximum deformation modulus.

The critical damage values of different unloading values of $90 \%, 85 \%, 80 \%$, and $70 \%$ were calculated to be $0.611,0.603,0.581$, and 0.569 , respectively. All of them are within the range of $P_{n}$ values, and proved the rationality of the investigated critical value.

Based on the critical damage value of Figure 13, one can realize that:

(1) Yu Shouwen, et al [19] considered the damage threshold range is between 0.2 and 0.8. Similarly, the damage threshold range was defined between 0.4 and 0.8 by XieLiyang, et al [20]. Gao Baobin, et al. [21-22] obtained the damage value of the rock sample failure into the residual stage through the test, which is about $0.650 \sim 0.670$. It is very close to the critical value $[0.500,0.618]$ obtained in this paper. The range is smaller, and the test results are within the damage critical value range determined by the renormalization theory. It proves the rationality of the established renormalization model and the critical value sought.

(2) The critical damage value decreases when the interaction coefficient increases from 0 to 1 . The relationship between the damage value and the interaction coefficient of sandstone is obtained by fitting, $p_{n}=0.141 \times e^{\left(\frac{-r}{0.505}\right)}+0.477$, and the corresponding correlation coefficient is 0.999 .

(3) The critical value of the damage was increasing wh-en the unloading values increased. This is because of the failure characteristics of the rock sample throughout the test, and complies with the assumption made in the previ-ous section. Therefore, it was logical to characterize the influence of different unloading values by using the inter-action coefficient.

\section{A model for time-lag failure of unloading damaged sandstone}

After unloading of the rock mass, the damage variable becomes less than 1 . The authors believed to predict theduration of sandstone unloading damage based on a critic-al value, and establish an equation to provide a theoretic-al basis. With the development of damage mechanics, theprevious researchers got many findings and established plenty of damage evolution models [23-27]. The developed models are either segmented or complicated. They have some limitations. The damage value of rock at the residualstrength stage is 1. According to Zhao Minghua et al. [28], the 
Logistic growth curve ("S" curve) is the process of occurrence, development, and maturity. Chudnovsky [29] believes that the process of rock deformation is a nonlinear growth and evolution process, and there is a process of occurrence, development and maturity. Wang Xiaorui [30] believes that the surrounding rock-time curve is shaped like an "S" when it is stable. It is feasible to use the Logistic model to analyze the growth curve. The total nu-mberof cracks and the damage evolution curve of rock showedan "S" shape cumulative growth during the process of failure (Wen Tao et al $[22,31]$ ). Therefore, the damageevolution process of rock specimens can be simulated by using the logistic model. However, at present, the researc-h on logistic growth model in geotechnical engineering mainly focuses on the prediction of soil foundation settle-ment, and there are few reports on the applied research, particularly on rock damage evolution. Based on this, the authors established a Logistic evolution model for the unloading rock damage (hereinafter referred to as R-L model). In Section 4, based on the renormalization group theory, the damage threshold of unloaded sandstone is obtained between $[0.500,0.618]$. Therefore, based on the specified range, the R-L model can be used to predict the ti-me range of the time-delayed damage of sandstone with different degrees of unloading damage.

The damage growth curve has the following characteristics:

(1) The curve does not pass through the origin. Naturally, rock masses are more or less damaged due to the different in-situ conditions.

(2) Monotonically increasing, as time progresses, dama-ge also increases.

(3) Damage is bounded. At a particular time, the damage value is steady.

The R-L model is as follows:

$$
\mathrm{D}_{t}=\frac{\left(a_{1}-a_{2}\right)}{\left(1+\left(\frac{t}{t_{0}}\right)\right)^{m}}+a_{2}
$$

In the above formula, $\mathrm{D} t$ is a predictable value for the damage at time $t$, and $a_{1}, a_{2}, m$, and $t_{0}$ are unknown coefficients. The initial damage of the rock reflected by $a_{1}$ is determined by the initial unloading value and the origin-al occurrence environment. $a_{2}$ is a parameter reflecting the critical damage value. $\mathrm{m}$ is a parameter that governs the convergence speed of the damage curve. $t_{0}$ is related to the time-lagged failure time. All parameters can be established by using a curve-fitting technique (Figure 14). Specific parameters are listed in Table 2.
Table 2 Parameters of R-L model for different unloading values

\begin{tabular}{lccccc}
\hline $\begin{array}{l}\text { unloading } \\
\text { values }\end{array}$ & $\mathrm{a}_{1}$ & $\mathrm{a}_{2}$ & $\mathrm{t}_{0}$ & $\mathrm{~m}$ & $\mathrm{R}^{2}$ \\
\hline $70 \%$ & 0.097 & 0.572 & 490.103 & 10054.177 & 0.964 \\
$80 \%$ & 0.105 & 0.582 & 160.277 & 1974.497 & 0.975 \\
$85 \%$ & 0.092 & 0.603 & 73.799 & 19607.140 & 0.995 \\
$90 \%$ & 0.092 & 0.611 & 32.396 & 2035.541 & 0.994 \\
\hline
\end{tabular}

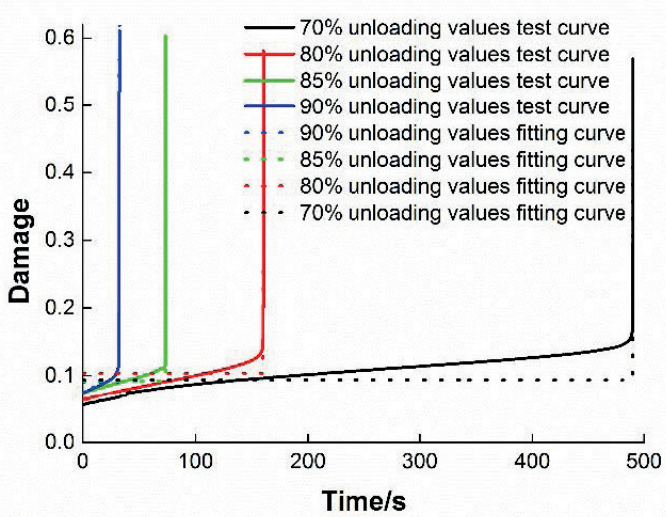

Fig. 14 Damage evolution curve of unloading and fitting curve for sandstone

(1) The experimental results can provide data support for the prediction model and verify the rationality of the model. Based on the calculation, the predicted time ranges of failure with different unloading values of $90 \%, 85 \%$, $80 \%$, and $70 \%$ are [32.416s, 33.874s], [73.804s, $73.833 \mathrm{~s}]$, $[160.400 \mathrm{~s}, 167.820 \mathrm{~s}]$, and $[490.190 \mathrm{~s}, 494.47 \mathrm{~s}]$, respectively. The measured timelag during the test was $30.504 \mathrm{~s}$, $72.687 \mathrm{~s}, 159.907 \mathrm{~s}$, and $489.698 \mathrm{~s}$. The error range is $[6.3 \%$, $11.1 \%],[1.5 \%, 1.6 \%],[0.3 \%, 4.9 \%]$, and $[0.1 \%, 1.0 \%]$. The error is almost within $5.0 \%$. Although the prediction error for $90 \%$ unloading is between $6.3 \%$ and $11.1 \%$, and its error range is only [1.912s, 3.370s] due to its small base. Relatively, the error is almost negligible, the overall prediction result is good, $\mathrm{R}^{2}$ are all above 0.96 , and the establishhed R-L model is reasonable.

(2) After the real excavation, it is necessary to calcula-te the unloading damage degree of different areas of the surrounding rock mass according to the stress state and excavation amounts of the surrounding rock mass, and thenpredict the duration of the damage by the prediction method proposed in this paper. It can provide reference for engineering support time and measures.

\section{Conclusions and discussion}

(1) During the time-delay test, the duration of rock sample failure decreases gradually while the unloading value increases (i.e., from 489.698 s and $30.504 \mathrm{~s}$ when the 
unloading was $70 \%$ and $90 \%$, respectively). The higher the unloading, the higher the rock fragmentation and the failure surface evolves from a single shear fracture to a multi-fork shear fracture. It shows that the duration of the time-delayed damage has a particular relationship with the integrity of the rock sample and is closely related to the unloading capacity.

(2) Based on the renormalization group theory, the interaction coefficient $r$ was introduced, and the renormalization model for the unloading damaged sandstone was established. The damage threshold range of unloaded sandstones was $[0.500,0.618]$. The rationality of the model was verified.

(3) After analyzing the damage curve trend, the Logistic growth model was introduced, and the duration of the time-delay damage for the unloaded sandstone was predicted by using the critical threshold range. The prediction result was found to be good. It can be used as a reference for similar engineering problems.

(4) It should be pointed out that the study of time-delay mechanism of unloading rock mass deformation is a very complex scientific problem, and the experiment in this paper was conducted by using $20 \mathrm{MPa}$ confining pressure. Further studies can be conducted to strengthen the current knowledge.

\section{Acknowledgement}

This work was supported by the National Nature Science foundation of China (No.51439003), National Nature Science foundation of China (No.51679127), National Nature Science foundation of China (No.51809151), the Research Fund for Excellent Dissertation of China Three Gorges University (No.2018BSPY002) and Key Laboratory of Geological Hazards on Three Gorges Reservoir Area (China Three Gorges University), Ministry of Education open fund project (No. 2018KDZ04).

\section{References}

[1] Ha, Q. L., Li, J. L., Zhang, Y. X., Liu, G. L. "Nonlinear mechanics of jointed rock during unloading", China Architecture and Building Press, Beijing, China, 1998. (in Chinese)

[2] Liu, N., Zhang, C. S., Chu, W. J. "Experimental research on time-dependent behavior of crack propagation in Jinping deep marble", Rock and Soil Mechanics, 33(8), pp. 2437-2450, 2012. (in Chinese) https://doi.org/10.3969/j.issn.1000-7598.2012.08.030

[3] Yu, H. C., Li, Y. L., Liu, H. D. "Comparative study of conventional mechanical, creep and stress relaxtion properties of silty mudstone under triaxial compression", Chinese Journal of Rock Mechanics and Engineering, 31(1), pp. 60-70, 2012. (in Chinese) https://doi.org/10.3969/j.issn.1000-6915.2012.01.008
[4] Yang, Y.-S., Zhou, H., Zhang, C.-Q., Zhang, K., Yan, F. "Experimental investigation on time-lag failure properties of marble under uniaxial compressive test", Rock and Soil Mechanics, 32(9), pp. 2714-2720, 2011. (in Chinese) https://doi.org/10.3969/j.issn.1000-7598.2011.09.026

[5] Ömer, A. "Time-Dependency in Rock Mechanics and Rock Engineering", 1st ed., CRC Press, London, UK, 2016. https://doi.org/10.1201/9781315375151

[6] Bagherpour, R., Rahimdel, M. J. "The Dangerous Condition of Ground duringHigh Overburden Tunneling (A Case Study in Iran)" Periodica Polytechnica Civil Engineering, 60(1), pp. 11-20, 2016. https://doi.org/10.3311/PPci.7923

[7] Zhang, L. J. "Study on time-lagged fracture characteristic of brittle rock under high press condition", China University of Geosciences, 2016. (in Chinese)

[8] Su, C.-D., Xiong, Z.-Q., Liu, S.-W., Wang, W. "Experimental study of time-lag deformation and failure properties of coal under uniaxial compression", Rock and Soil Mechanics, 37(3), pp. 665-671, 2016. (in Chinese)

https://doi.org/10.16285/j.rsm.2016.03.007

[9] Fan, Y., Lu, W., Wang, Y., Yan, P., Chen, M., "Comparison of evolution characteristics of immediate and time delayed rockbursts under different excavation methods", Chinese Journal of Rock Mechanics and Engineering, 34(2), pp. 3715-3723, 2015.

https://doi.org/10.13722/j.cnki.jrme.2014.1076

[10] Ma, T.-H., Tang, C.-A., Zhang, W.-D. "Time-deendent Deformation Mechanism of the Surrounding Rock with Delayed Rockburst Preparation Process", Research and Exploration in Laboratory, 33(9), pp. 4-9, 2014. (in Chinese) https://doi.org/10.3969/j.issn.1006-7167.2014.09.002

[11] Dahhaoui, H., Belayachi, N., Zadjaoui, A. "Modeling of creep behavior of an argillaceous rock by numerical homogenization method", Periodica Polytechnica Civil Engineering, 62(2), pp.462-469, 2018. https://doi.org/10.3311/PPci.11697

[12] Deng, H. F. "Study on the mechanism and effects of water-rock interaction under water level change region", Wuhan University, 2010. (in Chinese)

[13] Duan, L. P., Lu, J., Chen, J., Li, Y. "Application of renormalization group theory to critical behavior of water", Journal of Chemical Industry and Engineering, 54(1), pp. 18-23, 2003. (in Chinese) https://doi.org/10.3321/j.issn:0438-1157.2003.01.004

[14] Liang, Z.-Z., Tang, C.-A., Tang, S.-B., Xu, T., Zuo, Y.-J. "Characteristics of fractal and percolation of rocks subjected to uniaxial compression during their failure process", Chinese Journal of Rock Mechanics and Engineering, 29(9), pp. 1386-1391, 2007. (in Chinese)

https://doi.org/10.3321/j.issn:1000-4548.2007.09.017

[15] de Alcantara Bonfim, O. F., Engelsberg, M. "Large-cell Monte Carlo renormalization-group method for a new type of environmental percolation", Physical Review, 34(3), pp. 1977-1979, 1986. https://doi.org/10.1103/physrevb.34.1977

[16] Liu, Z., Zhou, C.-Y., Zhu, F.-X., Zhang, L., "Critical criterion for microstructure evolution of soft roc ks in softening process", Rock and Soil Mechanics, 32(3), pp. 661-666, 2011. (in Chinese) https://doi.org/10.16285/j.rsm.2011.03.013 
[17] Shi, S. B. "Research on the models of percolation rock fracture and flit ant on the real-space renormalization group approach", Msc, China, Hebei University of Technology, 2004. (in Chinese)

[18] Olami, Z., Feder, H. J. S., Christensen, K. "Self-organized criticality in a continuous, nonconservative cellular automaton modeling earthquakes", Physical Review Letters, 68(8), pp. 1244-1247, 1992. https://doi.org/10.1103/physrevlett.68.1244

[19] Yu, S. W., Feng, X. Q. "Damage mechanics", Tsinghua University Press, Beijing, China, 1997. (in Chinese)

[20] Xie, L. Y., Yu, F. "Analysis on Critical Fatigue Damage", Chinese Journal of Applied Mechanics, 11(3), pp. 57-60, 1994. (in Chinese)

[21] Gao, B.-B., Li, H.-G. "Research on Coal samples damage model based on acoustic emission parameters", Journal of Disaster Prevention and Mitigation Engineering, 34(1),pp. 101-106, 2014. https://doi.org/10.13409/j.cnki.jdpme.2014.01.016

[22] Ma, G. Q. "Constitutive Models of Half-homogeneous Sandstone Based on Damage Evolution", Journal of Yangtze River Scientific Research Institute, 35(6), pp. 86-91, 2018. (in Chinese)

[23] Løland, K. E. "Continuous damage model for load-response estimation of concrete", Cement and Concrete Research, 10(3), pp. 395-402, 1980.

https://doi.org/10.1016/0008-8846(80)90115-5

[24] Mazars, J. "A description of micro- and macroscale damage of concrete structures", Engineering Fracture Mechanics, 25(5-6), pp. 729-737, 1986.

https://doi.org/10.1016/0013-7944(86)90036-6

[25] Yang, X.-B., Qin, Y.-P., Ye, F. "Damage constitutive relation of sandstone considering residual stress", Journal of China Coal Society, 40(12), pp. 2807-2811, 2015. (in Chinese) https://doi.org/10.13225/j.cnki.jccs.2015.0141
[26] Shan, R., Song, Y., Song, L., Huang, P., Dai, X., Zhou, T. "Time dependent damage model of northwest artificia 1 frozen red sandstone under dynamic loading", Journal of China Coal Society, 43(1), pp. 118-123, 2018. (in Chinese) https://doi.org/10.13225/j.cnki.jccs.2017.0800

[27] Zhang, H.-M., Meng, X.-Z., Peng, C., Yang, G., Ye, W.-J., Shen, Y.-J., Liu, H. "Freeze-thaw damage model and parameters of rockdeformation in whole process", Journal of Xi'an university of science and technology, 2, pp. 260-265, 2018. (in Chinese) https://doi.org/10.13800/j.cnki.xakjdxxb.2018.0213

[28] Zhao, M.-H., Liu, Y., Cao, W.-G. "Study on variable-weight combination forecasting method of S-type curves for soft clay embankment settlement", Rock and Soil Mechanics, 26(9), pp. 1443-1447, 2005. (in Chinese) https://doi.org/10.3969/j.issn.1000-7598.2005.09.019

[29] Chudnovsky, A., Kachanov, M. "Interaction of a crack with a field of microcracks", International Journal of Engineering Science, 21(8), pp. 1009-1018, 1983. https://doi.org/10.1016/0020-7225(83)90078-2

[30] Wang, X.-R.,Wang, Y.-H. "Displacement Prediction of Surrounding Rock Mass of Yunling Tunnel by Logistic-Verhulst Model", Journal of Kunming University of Science and Technology (Science and Technology), 32(5), pp. 57-60. 2007. (in Chinese) https://doi.org/10.3969/j.issn.1007-855X.2007.05.014

[31] Tao, W. "Failure mechanism of rock under loading and unloading conditions and its application", Phd., China University of Geoscience, 2018. (in Chinese) 